\title{
Anne Elizabeth Cobby, The Old French Fabliaux. An Analytical Bibliography
}

\section{G. Matteo Roccati}

\section{Q OpenEdition}

10 Journals

\section{Édition électronique}

URL : https://journals.openedition.org/studifrancesi/2990

DOI : 10.4000/studifrancesi.2990

ISSN : 2421-5856

\section{Éditeur}

Rosenberg \& Sellier

\section{Édition imprimée}

Date de publication : 1 juillet 2013

Pagination : 429

ISSN : 0039-2944

\section{Référence électronique}

G. Matteo Roccati, «Anne Elizabeth Cobby, The Old French Fabliaux. An Analytical Bibliography », Studi Francesi [En ligne], 170 (LVII | II) | 2013, mis en ligne le 30 novembre 2015, consulté le 31 janvier 2023. URL : http://journals.openedition.org/studifrancesi/2990; DOI : https://doi.org/10.4000/studifrancesi. 2990

Ce document a été généré automatiquement le 31 janvier 2023.

\section{(c) $($ ) $\odot$ (8Y NO ND}

Creative Commons - Attribution - Pas d'Utilisation Commerciale - Pas de Modification 4.0 International - CC BY-NC-ND 4.0

https://creativecommons.org/licenses/by-nc-nd/4.0/ 


\title{
Anne Elizabeth Cobby, The Old French Fabliaux. An Analytical Bibliography
}

\author{
G. Matteo Roccati
}

\section{RÉFÉRENCE}

ANNE ELIZABETH COBBy, The Old French Fabliaux. An Analytical Bibliography, Woodbridge, Tamesis (Boydell \& Brewer), 2009 ("Research Bibliographies and Checklists. New Series", 9), pp. XvI-220.

1 Le volume récense 1045 titres (pour lesquels sont signalés aussi les compte rendus), depuis Claude Fauchet jusqu'à 2007; chaque item est identifié par un numéro et fait l'objet d'une brève notice, essentielle, claire et riche en renseignements. Le corpus est limité à celui du NRCF pour les éditions, à quelques exceptions près; il est plus large pour la critique (englobant tout texte présenté comme "fabliau"), les sources sont incluses, rarement la posterité. Après une première partie qui fournit les clés pour la consultation (Manuscripts, Fabliaux and Related Texts, Periodicals and Series, Frequently Cited Works, General Abbreviations), la bibliographie est organisée en quatre sections: A. Bibliographical Studies, B. Manuscript Studies, C. Editions. Translations, and Adaptations, D. Critical Studies. Trois index (Scholars, Mediaeval Texts and Authors, Subject Index; pp. 193-220) complètent le volume. 